\title{
Comparative Evaluation of Perioperative Haemodynamics and Emergence Profile Among Isoflurane, Sevoflurane and Desflurane in Patients Undergoing Elective Supratentorial Craniotomy for Space Occupying Lesion
}

\author{
Rakesh K Dubey ${ }^{1}$, Jitendra S Chahar', Deepak Malviya', Virendra Kumar ${ }^{3}$, Manoj Tripathi ${ }^{4}$ \\ ${ }^{1}$ Senior Resident, Department of Anesthesia and Critical Care, Dr. Ram Manohar Lohia Institute of Medical Sciences, Lucknow, Uttar Pradesh, India, \\ ${ }^{2}$ Professor, Department of Anesthesia and Critical Care, Dr. Ram Manohar Lohia Institute of Medical Sciences, Lucknow, Uttar Pradesh, India, ${ }^{3}$ Associate \\ Professor, Department of Anesthesia and Critical Care, Dr. Ram Manohar Lohia Institute of Medical Sciences, Lucknow, Uttar Pradesh, India, ${ }^{4}$ Assistant \\ Professor, Department of Anesthesia and Critical Care, Dr. Ram Manohar Lohia Institute of Medical Sciences, Lucknow, Uttar Pradesh, India
}

\section{Abstract}

Background: Introduction of sevoflurane and desflurane had increased anaesthetic choices for maintenance of general anesthesia in neurosurgical cases after isoflurane. Aims: To compare emergence characteristics, intraoperative haemodynamic and intraoperative brain relaxation between isoflurane, sevoflurane and desflurane in patients undergoing elective supratentorial craniotomy. Settings and Design: Randomized, prospective and comparative study. Subjects and Methods: In this study, recruited patients were randomly allocated in three groups. Groups I, S, and D received Isoflurane, sevoflurane and desflurane in MAC (0.8-1.2) during maintenance of general anesthesia after endotracheal intubation till skin closure. Emergence time, extubation time, perioperative hypertension and intraoperative brain relaxation were compared between 3 groups across different time period. Statistical Analysis: Mean and standard deviation were calculated. Test of analysis between two groups was done by t-test and among three groups by analysis of variance, and then P value was calculated. Results: Significantly lesser emergence time and extubation time was found in group D compared to group I and group S ( $7.53 \pm 2.11$ vs $15.10 \pm 1.74$ vs $10.50 \pm 1.19$ and $10.87 \pm 1.961$ vs $18.20 \pm 1.92$ vs $14.00 \pm 2.068$ ). Incidence of emergence hypertension and post-operative complication were found to be similar among 3 groups. Conclusion: It is concluded that although all 3 inhalational agents can be used in patients undergoing supratentorial surgeries, desflurane has added advantage of faster post-operative recovery and emergence characteristics.

Keywords: Isoflurane, desflurane, sevoflurane, supratentorial craniotomy, emergence time, extubation time, emergence hypertension.

Corresponding Author: Dr. Manoj Tripathi, Department of Anesthesia and Critical Care, Dr. Ram Manohar Lohia Institute of Medical Sciences, Lucknow, Uttar Pradesh, India.

Received: December 2018

Accepted: January 2019

\section{Introduction}

The practice of neuroanesthesia is continuously advancing. With increasing incidence of supratentorial space occupying lesion, the rate of craniotomies for these lesions is also increasing. The ideal anesthetic agent for these surgeries should preserve cerebral hemodynamics and provide rapid emergence to facilitate the early detection of postoperative deficit. $^{[1,2]}$

Inhalational volatile agents are commonly used for maintaining general anesthesia in these operations due to their ease of administration, the availability of end-tidal monitoring and predictable intra-operative and recovery characteristics. Older agents like halothane were associated with greater alteration in cerebral physiology and have been superseded by newer agents like isoflurane, sevoflurane and desflurane.
Isoflurane is commonly used volatile agent for maintenance during general anesthesia in India and considered an appropriate anesthetic for intracranial surgeries due to its better effect on cerebral physiology as well as the lowered cost compared with the other inhalational anesthetics, ${ }^{[3,4]}$

Introduction of less soluble agents like sevoflurane and desflurane had increased anaesthetic choices for maintenance of general anesthesia in neurosurgical cases.

There are numerous studies comparing isoflurane with desflurane or isoflurane with sevoflurane and sevoflurane with desflurane in neurosurgical patients. There is a single study comparing isoflurane, sevoflurane and desflurane in paediatric patients undergoing neurosurgery for supratentorial surgery.

The present study was carried out to assess and compare the effects of Isoflurane, sevoflurane and desflurane on hemodynamics, intraoperative brain relaxation and emergence characteristics (emergence time, extubation time, 
post-operative nausea and vomiting, and emergence hypertension) in adult patients undergoing elective supratentorial craniotomy for space occupying lesion and to find ideal anesthetic agent among three for supratentorial surgeries.

\section{Subjects and Methods}

The present study entitled "Comparative evaluation between Isoflurane, Sevoflurane and Desflurane in patients undergoing elective supratentorial craniotomy for space occupying lesion" was conducted at the Department of Anesthesiology and Critical care Medicine (Dr. Ram Manohar Lohia Institute of Medical sciences), a tertiary care hospital \& research Centre for period of 1.5 years. Ethical approval for this study (Ethical Committee $\mathrm{N}^{\circ}$ 55/15) was provided by the Ethical Committee of KGMU university Dr RMLIMS hospitals, lucknow, India (Chairperson Prof D. Malviya)) on 11 march 2016 . Informed consent was obtained from each patient prior to inclusion into the study with choice to withdraw from the study at any time, without giving any reason and without impact on treatment. A register was kept of all patients evaluated for inclusion and of patient who chose to withdraw from the study. The study included 90 patients with American Society of Anaesthesiologists (ASA) status I and II of either sex in the age group of 20-60 years and Glasgow coma score $>12$ undergoing supratentorial craniotomy for space occupying lesion. Patients with the following conditions were excluded from the study: Patient refusal to give consent, ASA physical status $3 \& 4$, Age $<20$ and $>60$ years either sex, Glasgow coma score $<12$, patient with heart disease, hypertension, diabetes mellitus, COPD, hepatic and renal dysfunction, patients who had surgery related complications like vascular injury, massive intraoperative bleeding or injury to vital structures necessitating elective postoperative mechanical ventilation and patients with previous cranial surgery.

The primary outcome measures were: Emergence characteristics in term of- Emergence time (defined as time elapsing from end of anaesthesia until patients were able to open their eyes), Tracheal Extubation Time (defined as time elapsing from discontinuation of inhalational anaesthetics to extubation after spontaneous ventilation), Emergence hypertension, Post-operative nausea and vomiting, shivering and awareness. Secondary outcomes were-, Intraoperative brain relaxation, Intraoperative Haemodynamic i.e. Heart rate (HR) and Mean Arterial pressure (MAP).

Sample size was estimated based on mean extubation time of 15.2 minutes with sevoflurane and 11.3 minutes with desflurane in a recent study. ${ }^{[5]}$ To detect a $25 \%$ decrease in extubation time with standard deviation (S.D.) of 3.5, the calculated sample size was 22 per group at a power of $90 \%$ and confidence interval of $95 \%$ with an effect size of 1.1 . To have adequate power of study despite possible dropouts and exclusion because of surgical reasons, the sample size was increased to 30 patients per group. Using computer generated randomization list, the patients were randomly allocated to one of the 3 groups of 30 each.

Group I: Isoflurane +oxygen and air [50\%: 50\%]

Group S: Sevoflurane+ oxygen and air [50\%: 50\%]

Group D: Desflurane + oxygen and air [50\%: 50\%]

After taking $18 \mathrm{~g}$ intravenous access in preoperative room, all patients were shifted to operating room. In operation theatre multichannel physiologic parameters were attached like Noninvasive blood pressure (NIBP), Pulse Oximetry, Electrocardiogram (ECG) and $18 \mathrm{~g}$ intravenous access was taken. Patients were premedicated with Midazolam $(.05 \mathrm{mg} / \mathrm{kg})$ i.v. and Fentanyl $(2-3 \mathrm{mcg} / \mathrm{kg})$ i.v. General anaesthesia was induced with thiopentone $(3-5 \mathrm{mg} / \mathrm{kg})$ i.v. till loss of eyelash reflex and vecuronium $(0.1 \mathrm{mg} / \mathrm{kg})$ i.v. was given to facilitate tracheal intubation. Central venous cannulation with $7 \mathrm{fr}$ CVP catheter in right internal jugular vein and arterial (radial) cannulation with $22 \mathrm{~g}$ intravenous catheter were performed following tracheal intubation. Temperature monitoring was done using nasopharyngeal probe and urine output was monitored hourly following Foley's catheterization. Mechanical ventilation was adjusted to achieve a $\mathrm{PaCO} 2$ of $30 \pm 2 \mathrm{~mm} \mathrm{Hg}$ and the inhaled anaesthetic concentration was adjusted to obtain a minimum alveolar concentration (MAC) between 0.8 and 1.2. The endtidal concentrations of the volatile anaesthetics and the ETCO2 were monitored continuously. After achieving a steady anaesthetic state, fresh gas flow rate was maintained at $2 \mathrm{~L} / \mathrm{min}$. Intermittent boluses of vecuronium $(0.01-$ $0.02 \mathrm{mg} / \mathrm{kg}$ ) i.v. were given as and when required. Dexamethasone $8 \mathrm{mg}$ i.v and antibiotics were given as required by the surgical procedure. Before pin insertion, Skull pin sites were infiltrated with $2 \%$ lignocaine solution and fentanyl $1 \mathrm{mcg} / \mathrm{kg}$ i.v. and propofol $0.5 \mathrm{mg} / \mathrm{kg}$ i.v. were given accordingly. Starting with skin incision, mannitol (0.5 $\mathrm{g} / \mathrm{kg}$ ) i.v. was administered over a period of 20-30 minutes.

After dural opening, the attending neurosurgeon, who was blinded to the study groups, assessed the brain condition on a 3-point scale:

1. Perfectly relaxed,

2. Satisfactory relaxation,

3. Tight brain.

Intervention like change in position, further reduction of $\mathrm{PaCO} 2$, additional mannitol or furosemide was undertaken when brain condition was of grade 3 .

Heart rate (HR) and Mean arterial blood pressure (MAP) were recorded as baseline (before anaesthesia induction), immediately after intubation and subsequently at $30 \mathrm{~min}$ interval till the time of tapering the inhalational agents. Thereafter, vitals were recorded immediately after tracheal extubation and then at $15 \mathrm{~min}$ interval till $1 \mathrm{hr}$ following surgery.

MAP $>20 \%$ above baseline and or HR $>100 /$ min or $>20 \%$ above baseline was treated with increasing the inspired concentration of isoflurane, sevoflurane or desflurane upto 1.2 MAC followed by fentanyl $0.5-1 \mathrm{mcg} / \mathrm{kg}$ i.v bolus, propofol $0.5 \mathrm{mg} / \mathrm{kg}$ slow intravenous (IV) bolus and then labetalol (5 mg increments) if required. Decrease of MAP to $<20 \%$ below the baseline value was treated by decreasing the inhaled anaesthetic agents up to the level of $0.8 \mathrm{MAC}$ and bolus of IV fluids. Failure of blood pressure response to those agents was managed with administration of mephentermine (5mg Increments). Bradycardia (as defined by $\mathrm{HR}<40 / \mathrm{min}$ for $>1 \mathrm{~min}$ ) was managed with atropine (0.6mg i.v. bolus till max of $3 \mathrm{mg}$ i.v.). Normal body temperature was maintained using a forced-air warming blanket. All patients received ondansetron $(0.1 \mathrm{mg} / \mathrm{kg})$ i.v. and paracetamol $(15 \mathrm{mg} / \mathrm{kg})$ i.v. 30 minutes before end of 
surgery. Isoflurane, Sevoflurane and Desflurane was tapered at the beginning of skin suturing and stopped after skin dressing. Neuromuscular blockade was reversed with neostigmine $0.05 \mathrm{mg} / \mathrm{kg}$ i.v. and glycopyrrolate $0.01 \mathrm{mg} / \mathrm{kg}$ i.v. The trachea was extubated after checking adequate reversal of neuromuscular blockade, return of spontaneous respiration, maintenance of adequate oxygen saturation on the pulse oximeter and when the patient followed commands. MAP $>20 \%$ above baseline during emergence were treated with injection labetalol (5 mg increments). All patients were shifted to post anesthesia care unit after tracheal extubation.

Patients were observed for $1 \mathrm{~h}$ for monitoring of postoperative complications like Post-operative nausea and vomiting, emergence agitation and shivering. Emergence hypertension was also noted. All the patients were interviewed on the second postoperative day for awareness during anesthesia using the modified Brice interview. ${ }^{[6]}$

\section{Statistical Analysis}

Data obtained from the patients under study were recorded in a standard Performa. The parametric data were expressed as mean \pm standard deviation. Test for analysis among three groups was done by analysis of variance (ANOVA) for quantitative and Chi-square test for qualitative data. Comparison between two groups was done by t-test. A P value of $<0.05$ was considered statistically significant and a $\mathrm{P}>0.05$ was not considered statistically significant.

\section{Results}

\begin{tabular}{|c|c|c|c|c|}
\hline Parameter & $\begin{array}{l}\text { Isofluran } \\
\text { e }(n=30)\end{array}$ & $\begin{array}{l}\text { Sevoflura } \\
\text { ne }(n=30)\end{array}$ & $\begin{array}{l}\text { Desflura } \\
\text { ne } \\
(n=30)\end{array}$ & $\mathrm{P}$ \\
\hline Age (years) & $\begin{array}{l}38.37 \pm 11 \\
56\end{array}$ & $\begin{array}{l}32.67 \pm 10.5 \\
8\end{array}$ & $\begin{array}{l}36.13 \pm 10 \\
85\end{array}$ & $\begin{array}{l}0.1 \\
3\end{array}$ \\
\hline Sex (male/female) & $17 / 13$ & $14 / 16$ & $15 / 15$ & $\begin{array}{l}0.7 \\
3\end{array}$ \\
\hline ASA class (I/II) & $21 / 9$ & $19 / 1$ & $20 / 10$ & $\begin{array}{l}0.9 \\
4\end{array}$ \\
\hline $\begin{array}{l}\text { Tumour rype } \\
\text { (astrocyte/glioma/meningi } \\
\text { oma) }\end{array}$ & $2 / 21 / 7$ & $0 / 20 / 10$ & $2 / 20 / 8$ & $\begin{array}{l}0.8 \\
1\end{array}$ \\
\hline $\begin{array}{l}\text { Duration of anaesthesia } \\
\text { (h) }\end{array}$ & $3.32 \pm 1.04$ & $3.14 \pm 1.14$ & $3.11 \pm 1.16$ & $\begin{array}{l}0.6 \\
0\end{array}$ \\
\hline $\begin{array}{l}\text { Intravenous fluids infused } \\
\text { (L) }\end{array}$ & $3.15 \pm 0.80$ & $3.14 \pm 0.97$ & $3.32 \pm 0.73$ & $\begin{array}{l}0.7 \\
0\end{array}$ \\
\hline Estimated blood loss (L) & $0.39 \pm 0.19$ & $0.41 \pm 0.21$ & $0.40 \pm 0.15$ & $\begin{array}{l}0.9 \\
4\end{array}$ \\
\hline Urine output (L) & $1.12 \pm 0.67$ & $0.94 \pm 0.65$ & $1.10 \pm 0.70$ & $\begin{array}{l}0.5 \\
8\end{array}$ \\
\hline
\end{tabular}

Ninety patients undergoing surgery for supratentorial tumour resection between March 2016 and August 2017 were enrolled in the study. The demographic profile, total duration of anaesthesia and intraoperative data were comparable in the three groups [Table 1]. The Heart Rate both intraoperatively and post extubation was found to be higher in isoflurane group compared to that in sevoflurane group and desflurane group. However the differences in HR were found to be statistically insignificant among groups across all time periods [Figure 1]. After comparing MAP among the groups, $\mathrm{p}$ values were found similar across different time periods with increase at time of intubation, pin insertion and extubation. Overall there was no significant difference found among three groups. [Figure 2]. The emergence time was longest in group I and shortest in group D $(15.10 \pm 1.74 \mathrm{~min}$ vs $10.50 \pm 1.19 \mathrm{~min}$ vs $7.53 \pm 2.11 \mathrm{~min}$ ). The difference in emergence time among 3 groups was highly significant with $\mathrm{p}$ value 0.001 [Table 2]. Similarly the extubation time was shorter in Group D when compared to group S and group I $(10.87 \pm 1.96 \mathrm{~min}$ vs $14.00 \pm 2.06 \mathrm{~min}$ vs $18.20 \pm 1.92 \mathrm{~min})$. The difference in extubation time among 3 groups was highly significant with $\mathrm{p}$ value 0.001 [Table 2]. As judged by operating Neurosurgeon intraoperative brain relaxation was comparable among 3 groups. $22(73.3 \%)$ patient in the desflurane group has grade 1 brain swelling comparing to 16 $(53.3 \%)$ patients in isoflurane group and $19(63.3 \%)$ patients in sevoflurane group. However with $p$ value 0.270 statistically insignificant difference was found among groups in brain relaxation grading [Table 3]. The incidence of postoperative complications was comparable among the three groups [Table 4]. 13 patients in desflurane had emergence hypertension comparable to 9 patients in sevoflurane and 8 patients in isoflurane groups. None of the patients in the three groups had any incidence of awareness under anaesthesia [Table 4].

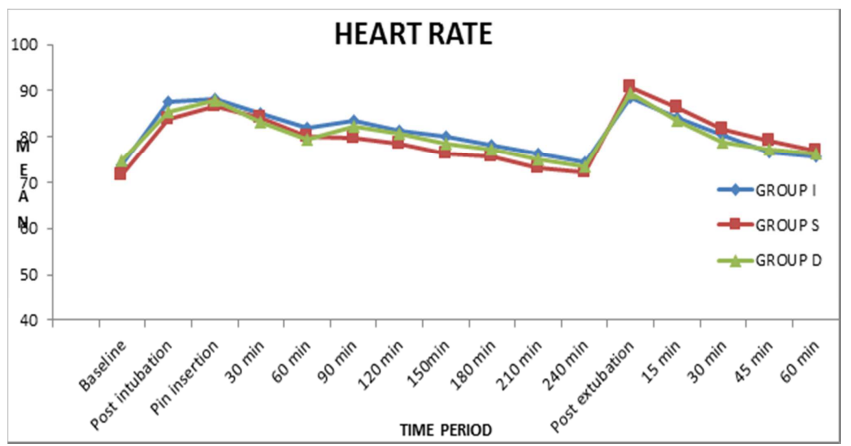

Figure 1: Data of heart rate at different stages of study period. $\# \mathbf{P}<0.05$, comparing three groups at various time points



Figure 2: Data of MAP (intraoperative) comparing three groups at various time points 


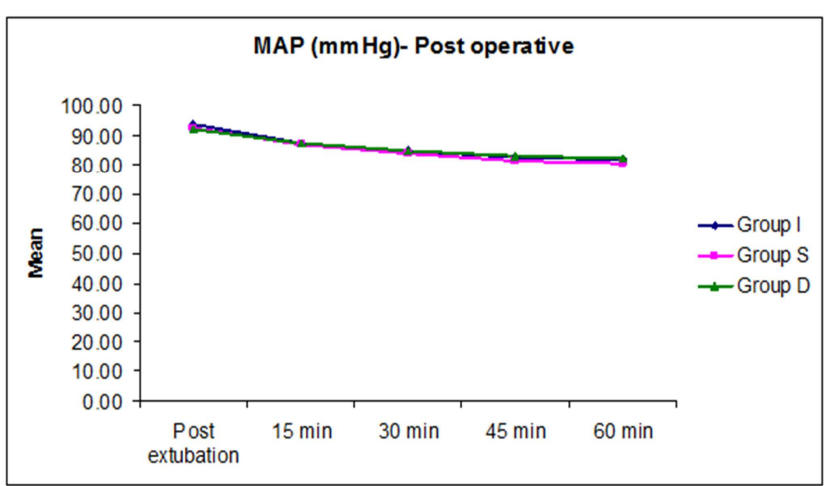

Figure 3: Data of MAP (Postoperative) comparing three groups at various time point

Table 2: Emergence And Extubation Time Among 3 Groups

\begin{tabular}{|l|l|l|l|l|}
\hline Parameter & GROUP-I & GROUP-S & GROUP-D & $\begin{array}{l}\text { p- } \\
\text { value }\end{array}$ \\
\hline $\begin{array}{l}\text { Emergence } \\
\text { time(min) }\end{array}$ & $15.10 \pm 1.74$ & $10.50 \pm 1.19$ & $7.53 \pm 2.11$ & 0.001 \\
\hline $\begin{array}{l}\text { Extubation } \\
\text { time(min) } \\
\text { (Mean } \pm \text { SD) }\end{array}$ & $18.20 \pm 1.92$ & $14.00 \pm 2.068$ & $10.87 \pm 1.961$ & 0.001 \\
\hline \\
Values expressed as mean \pm SD/number of patients. SD: standard deviation \\
\hline
\end{tabular}

Table 3: Intraoperative Brain Relaxation Grade Among 3 Groups

\begin{tabular}{|c|c|c|c|c|}
\hline \multirow{2}{*}{$\begin{array}{l}\text { Brain } \\
\text { Grade }\end{array}$} & \multicolumn{3}{|l|}{ Group } & \multirow[t]{2}{*}{ P Value } \\
\hline & GROUP I & GROUP S & GROUP D & \\
\hline 1 & 16 & 19 & 22 & \multirow[t]{3}{*}{0.27} \\
\hline 2 & 10 & 9 & 8 & \\
\hline 3 & 4 & 2 & 0 & \\
\hline
\end{tabular}

Table 4: Incidence of Post-operative complication in different groups

\begin{tabular}{|l|l|l|l|c|}
\hline \multirow{2}{*}{$\begin{array}{c}\text { Complicatio } \\
\text { n }\end{array}$} & \multicolumn{1}{|c|}{$\begin{array}{c}\text { Group } \\
\text { (Isoflurane) }\end{array}$} & $\begin{array}{c}\text { Group S } \\
\text { (Sevoflurane) }\end{array}$ & $\begin{array}{c}\text { Group D } \\
\text { value } \\
\text { (Desfluran } \\
\text { e) }\end{array}$ & \\
\hline PONV & 2 & 0 & 2 & 0.35 \\
\hline Agitation & 0 & 3 & 2 & 0.22 \\
\hline Shivering & 6 & 8 & 7 & 0.83 \\
\hline $\begin{array}{l}\text { Emergence } \\
\text { HTN }\end{array}$ & 8 & 9 & 13 & 0.35 \\
\hline Convulsions & 0 & 2 & 2 & 0.33 \\
\hline Awareness & 0 & 0 & $0^{*}$ & \\
\hline Varrennn
\end{tabular}

Values are mean $\pm \mathrm{SD} /$ numbers, *unable to assess in one patient due to motor aphasia, PONV: Postoperative nausea and vomiting,

\section{Discussion}

The search for an ideal anaesthetic agent, which fulfils the neuroanaesthetic goal, has now ushered us into an era whereby sevoflurane and desflurane have gained popularity. [Table 1] shows demographic comparison and intraoperative characteristics among 3 groups. This was found to be comparable, thereby removing any confounding effect.

Maintaining stable haemodynamic during surgery is an important part of the neuroanesthesia practice. Our patients had similar haemodynamic profile with the use of three agents at most of the observations during the study period. Isoflurane had a greater influence on the HR in our study, which is analogous to a multicentre trial whereby isoflurane use was associated with significant higher HR ${ }^{[8]}$ Ghoneim et al. ${ }^{[9]}$ compared isoflurane, sevoflurane and desflurane in paediatrics patients and found comparable HR and mean blood pressure in all 3 groups. Karamehmet Yildiz et al, ${ }^{[10]}$ in there study Comparison of 1 Minimum Alveolar Concentration Desflurane and 1 Minimum Alveolar Concentration Isoflurane Anaesthesia in patients undergoing Craniotomy for Supratentorial Lesions in 70 patients found no significant difference in HR between the 2 groups. Dubey et al. ${ }^{[11]}$ concluded that in patients undergoing elective supratentorial craniotomy both sevoflurane and desflurane had similar intra-operative brain condition and hemodynamics. Priska et al. ${ }^{[12]}$ compared propofol, sevoflurane and desflurane in 75 adult patients divided in 3 groups undergoing elective craniotomy for supratentorial tumours and found that the mean arterial blood pressure during anaesthesia was comparable among the groups.

No remarkable tachycardia or hypertension could be detected during the administration of the inhalational anaesthetics in the current study. These findings are most likely related to the relative stability of the end-tidal anaesthetic concentration throughout the surgery and the simultaneous repetition of both fentanyl and muscle relaxant throughout the anaesthesia. Cahalan et al. ${ }^{[13]}$ studied heart rate (HR) response to enflurane, halothane, and isoflurane and the effects of narcotics on this response in 81 healthy patients scheduled for elective surgery and concluded that prior administration of morphine or concurrent administration of fentanyl may significantly decrease HR when used with inhalational anaesthetics in clinical settings.

Rapid awakening after craniotomy with general anaesthesia help in an early diagnosis of postoperative neurologic complications which is essential to limit potentially devastating consequences and improve patient outcome. In our study we found significantly lesser emergence and extubation time in desflurane group when compared to isoflurane and sevoflurane group. Desflurane has low bloodgas and tissue-blood partition coefficients leading to a more rapid wash in and wash-out when compared with other volatile anaesthetics. ${ }^{[14]}$ Based on this pharmacokinetic properties of desflurane, recovery times were assumed to be faster, and our results approved this hypothesis. Wolf et al. ${ }^{[15]}$ studied 20 infants undergoing general anaesthesia for pyloromyotomy with either desflurane or isoflurane and reached to similar results; they observed that approximately twice the speed of recovery was elicited with desflurane anaesthesia when compared with isoflurane. Heavner et al. ${ }^{[16]}$ observed a significantly faster time to extubation, eye opening and orientation with desflurane than sevoflurane after various surgeries. Nathanson et al. ${ }^{[17]}$ reported the mean emergence time $(4.8 \pm 2.4$ vs. $7.8 \pm 3.8 \mathrm{~min})$ and extubation time $(5.1 \pm 2.2$ vs. $8.2 \pm 4.2 \mathrm{~min})$ to be significantly less with desflurane as compared to sevoflurane in outpatient surgeries but the recovery of cognitive function and discharge times from the hospital were similar between the two. In their study on neurosurgical patients, Magni et al. ${ }^{[18]}$ reported similar emergence time $(12.2 \pm 4.9 \mathrm{~min}$ vs. $10.8 \pm 7.2 \mathrm{~min}$ with $\mathrm{p}=0.32)$ but longer tracheal extubation time $(18.2 \pm 2.3$ $\min$ vs. $11.3 \pm 3.9 \mathrm{~min}, \mathrm{p}<0.001)$ and recovery time $(12.4 \pm$ 7.7 min vs. $1.3 \pm 3.9 \mathrm{~min}, \mathrm{p}<0.001)$ in the sevoflurane compared to the desflurane group. Gauthier et al. [19] reported that the emergence time, extubation time and 
orientation time was shorter in sevoflurane group compared to isoflurane group in neurosurgical patients.

Thus our results are similar to above studies. Although reducing isoflurane gradually towards the end of the operation may reduce the time-to-extubation and emergence, the quality of recovery is different for the three agents, particularly with regard to the psychomotor function. Although the quality of recovery was not determined in our study, patients who received desflurane were more alert.

Slack brain provides a good surgical field and reduces the need for brain retraction. ${ }^{[6]}$ As increased brain retraction pressure is related to the occurrence of regional cerebral dysfunction, ${ }^{[20]}$ we wanted good brain relaxation during surgery. In our study we found comparable brain relaxation among 3 groups with most patients having grade I. Although our study was not powered to detect differences in brain relaxation between the three anaesthetic strategies, our finding is consistent with the findings of Todd et al. ${ }^{[21]}$ who described a $10 \%$ incidence of brain swelling in patients undergoing neurosurgical resection of tumours while receiving isoflurane anaesthesia. Turner et al. ${ }^{[22]}$ found in his study that there is a low association between the degree of brain swelling and lumbar cerebrospinal fluid pressure so long the intracranial pressure maintained within the normal range for pressure values. We did not measure ICP during the study but instead relied on clinical evaluation by a blinded neurosurgeon to assess the influence of the three anaesthetics on brain relaxation. Systemic hypertension is a major drawback seen with early emergence, which may predispose to formation of intracranial hematoma. ${ }^{[23]}$ The occurrence of hypertension during emergence has been reported to be more than $90 \%$ in neurosurgical patients. In our study 13 patients in desflurane had emergence hypertension comparable to 9 patients in sevoflurane and 8 patients in isoflurane groups with $\mathrm{p}$ value- 0.350 no significant differences were seen among groups. The incidence of PONV was also found to be comparable. The results of our study are similar to previously published studies, which did not demonstrate any significant difference in the incidence of early postoperative complication with use of different anaesthetic agents. ${ }^{[24]}$ Wallenborn $\mathrm{J}$ et al, ${ }^{[25]}$ in there study, the impact of isoflurane, desflurane, or sevoflurane on the frequency and severity of postoperative nausea and vomiting after lumbar disc surgery and found that type of inhalation anaesthetic had no influence on PONV frequency.

The present study has limitations of its own. Monitoring of ICP would have been ideal instead of relying on surgeon satisfaction. With growing trend of reducing anesthesia related cost, the added costs associated with the use of desflurane and sevoflurane will determine their fate in long term. However use of desflurane results in shorter post anesthesia care unit duration. So it is recommended to assess the cost weighted against the rapid recovery and short duration of stay in the recovery room against the increased costs associated with the use of desflurane

The present study is a preliminary trial. The results of the present study need to be corroborated by conducting a large multicentre randomised clinical trial.

\section{Conclusion}

In this study, it can be concluded that although all 3 inhalational agents isoflurane, sevoflurane and desflurane can be used in patients undergoing supratentorial surgeries, desflurane has added advantage of faster post-operative recovery and intraoperative brain relaxation and emergence characteristics.

\section{References}

1. Schifilliti D, Grasso G, Conti A, Fodale V. Anaesthetic-related neuroprotection: intravenous or inhalational agents? CNS Drugs 2010;24:893-937.

2. Bruder N, Ravussin PA. Supratentorial masses: Anaesthetic considerations. In: Cottrell JE, Young WL, editors. Cottrell and Young's Neuroanaesthesia. 5th ed. Philadelphia: Elsevier; 2010. p. 184-202.

3. Stoelting RK, Hillier SC, editors. Inhaled anaesthetics. In: Pharmacology and Physiology in Anaesthetic Practice. 4th ed. Philadelphia: Lippincott Williams and Wilkins; 2006.p. 42-86.

4. Newberg LA, Milde J. The cerebral metabolic effects of isoflurane at and above concentrations that suppress cortical electrical activity. Anesthesiology 1983;59:23-28

5. Bruder N.J. Awakening management after neurosurgery for intracranial tumours. Curr Opin Anesthesiol 2002;15:477- 82.

6. Enlund M, Hassan HG. Intraoperative awareness: Detected by the structured Brice interview? Acta Anaesthesiol Scand 2002;46:345-9.

7. Basali A, Mascha EJ, Kalfas I, Schubert A. Relation between perioperative hypertension and intracranial hemorrhage after craniotomy. Anesthesiology 2000; 93:48-54.

8. Chen TL1, Yang SF, Chang HC, Tai YT, Li NL, Lin CJ.Comparison of hemodynamics and recovery of sevoflurane and isoflurane anesthesia in Chinese adult patients. ActaAnaesthesiol Sin. 1998; 36(1):31-6.

9. Ghoneim, Ayman A. Awakening properties of Isoflurane, sevoflurane and desflurane in paediatric patients after craniotomy for supratentorial tumours. J Neurosurgical Anesthesiol 2009;27:1-6.

10. Karamehmet Y, Cihangir B, Recep A, Kudret D. A Comparison of 1 Minimum Alveolar Concentration Desflurane and 1 Minimum Alveolar Concentration Isoflurane Anesthesia in Patients Undergoing Craniotomy for Supratentorial Lesions. Curr Ther Res Clin Exp 2011;72: 49-59.

11. Dubey SK, Pandia MP, Chaturvedi A, Bithal P, Dash HH.Comparison of intraoperative brain condition, hemodynamics and postoperative recovery between desflurane and sevoflurane in patients undergoing supratentorial craniotomy. Saudi J Anaesth 2015;9:167-73.

12. Priska B, Hemant B. Comparative evaluation of propofol, sevoflurane and desflurane for neuroanesthesia: A prospective randomized study in patients undergoing elective supratentorial craniotomy. In J Anesthesia 2015;59:5-16.

13. Cahalan MK, Lurz FW, Eger EI, Shwartz LA, Smith JJ. Narcotics decrease heart rate during inhalational anesthesia. Anesth Analg 1989;66:166-70.

14. Castillo LR, Gopinath S, Robertson CS. Management of intracranial hypertension. Neurol Clin 2008;26:521-4.

15. Wolf A, Lawson A, Dryden M, Davies FW. Recovery after desflurane anaesthesia in the infant: Comparison with isoflurane. Br. J. Anaesth 1996;76: 362-404.

16. Heavner JE, Kaye AD, Lin BK, King T. Recovery of elderly patients from two or more hours of desflurane or sevoflurane anesthesia. Br J Anesth 2003;91:502-6.

17. Nathanson MH, Fredman B, Smith I, White PF. Sevoflurane versus desflurane for outpatient anesthesia: A comparison of maintenance and recovery profiles. Anesth Analg 1995;81:1186-90.

18. Magni G, Rosa IL, Melillo G, Savio A, Rosa G. A comparison between sevoflurane and desflurane anesthesia in patients undergoing craniotomy for supratentorial intracranial surgery. Anesth Analg 2009; 109:567-71.

19. Gauthier A, Girard F, Boudreault D, Ruel M, Todorov A. Sevoflurane provides faster recovery and postoperative neurological assessment than isoflurane in long-duration neurosurgical cases. Anesth Analg 2002;95:1384-1408. 
20. Herrick IA, Gelb AW, Manninen PH, Reichman H, Lownie S. Effects of fentanyl, sufentanil, and alfentanil on brain retractor pressure. Anesth Analg 1991;72:359-63.

21. Todd MM, Warner DS, Sokoll MD, Maktabi MA, Hindman BJ, Scamman FL, et al. A prospective, comparative trial of three anesthetics for elective supratentorial craniotomy. Propofol/ fentanyl, isoflurane/nitrous oxide, and fentanyl/nitrous oxide. Anesthesiology 1993;78:1005-20.

22. Turner CR, Lossaco TJ, Muzzi DA. Brain relaxation and cerebral fluid pressure during craniotomy for resection of supratentorial mass lesions. J Neurosurg Anesthesiol 1996;8:126-32
23. Basali A, Mascha EJ, Kalfas I, Schubert A. Relation between perioperative hypertension and intracranial hemorrhage after craniotomy. Anesthesiology 2000;93:48-54.

24. Rosa G, Pinto G, Orsi P, de Blasi RA, Conti G, Sanita R . Control of post anaesthetic shivering with nefopam hydrochloride in mildly hypothermic patients after neurosurgery. Acta Anaesthesio Scand 1995;39:90-5.

25. Wallenborn J, Rudolph C, Gelbrich G, Goerlich TM, Helm J, Olthoff D. The impact of isoflurane, desflurane, or sevoflurane on the frequency and severity of postoperative nausea and vomiting after lumbar disc surgery. J Clin Anesth. 2007;19:180-205.

Copyright: (๑) the author(s), publisher. Academia Anesthesiologica International is an Official Publication of "Society for Health Care \& Research Development". It is an open-access article distributed under the terms of the Creative Commons Attribution Non-Commercial License, which permits unrestricted non-commercial use, distribution, and reproduction in any medium, provided the original work is properly cited.

How to cite this article: Dubey RK, Chahar JS, Malviya D, Kumar V, Tripathi M. Comparative Evaluation of Perioperative Haemodynamics and Emergence Profile Among Isoflurane, Sevoflurane and Desflurane in Patients Undergoing Elective Supratentorial Craniotomy for Space Occupying Lesion. Acad. Anesthesiol. Int. 2018;3(2):7-12.

DOI: dx.doi.org/10.21276/aan.2018.3.2.2

Source of Support: Nil, Conflict of Interest: None declared. 